\title{
STERNOPLASTY FOR INCOMPLETE STERNUM SEPARATION
}

\author{
Francis Robicsek, MD, PhD, Joseph W. Cook, MD, and Walter Rizzoni, MD, Charlotte, N.C.
}

In 1977 on the pages of this Journal, we ${ }^{1}$ presented a method designed to surgically treat poststernotomy sternal separation (Fig. 1). Since then the procedure has been generally accepted and widely applied.

The procedure, called sternal weaving by some, consists of placing peristernal bilateral double-row wire sutures and then reuniting the separated sternal halves with transverse sutures buttressed by the two double axial suture lines. The technique was later modified to include presternal pectoralis "muscle padding." 2

Although this method proved satisfactory in most cases in which the stability of the sternum was compromised in the entire length of the sternotomy incision, we encountered several patients with chronic sternal separation in whom the instability or separation of the sternum did not include the entire sternal body but was limited to the lower portion, leaving the upper sternum unified and healed. The management of those cases constituted somewhat of a dilemma because as a rule the separated halves of the lower sternum did not remain adjacent but moved away from each other creating a gap in the form of a reversed "V." To approximate the separated parts simply by suturing them together usually failed because of this preexisting gap, and even if it was successful, they remained under considerable tension, which in some instances led to "reseparation." Thus, most of the time, to reapproximate the lower portion properly, the manubrium that

From The Carolinas Medical Center, Charlotte, N.C.

Received for publication Feb. 19. 1998; accepted for publication Feb. 23, 1998.

Address for reprints: Francis Robicsek, MD, 1001 Blythe Blvd., Suite 300, Charlotte, NC 28203.

J Thorac Cardiovasc Surg 1998;116:361-2

Copyright (c) 1998 by Mosby, Inc.

$0022-5223 / 98 \$ 5.00+0 \quad \mathbf{1 2 / 5 4 / 8 9 8 0 3}$

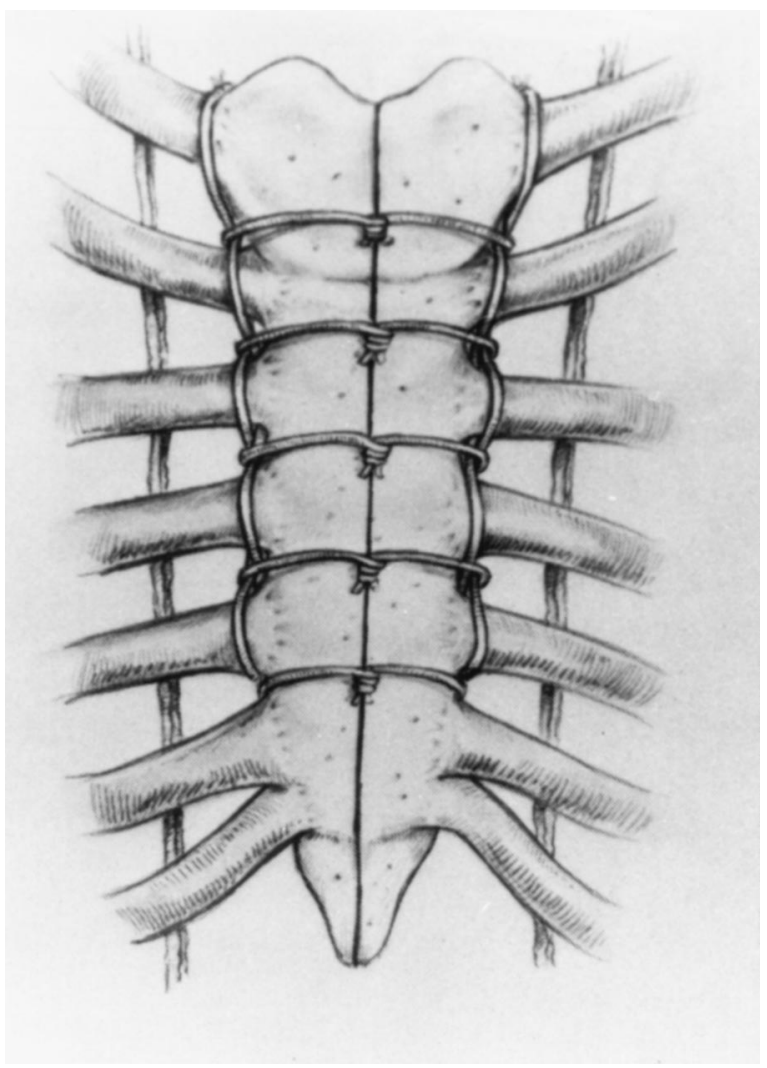

Fig. 1. "Conventional" sternum weave. (From Robicsek F, Daugherty HK, Cook JW. The Prevention and Treatment of Sterum Separation Following Open-Heart Surgery. J Thorac Cardiovasc Surg 1977;73:267-8.)

healed well also had to be divided with all the risk and inconvenience of a "full" resternotomy just to be able to reapproximate the lower portion properly. 


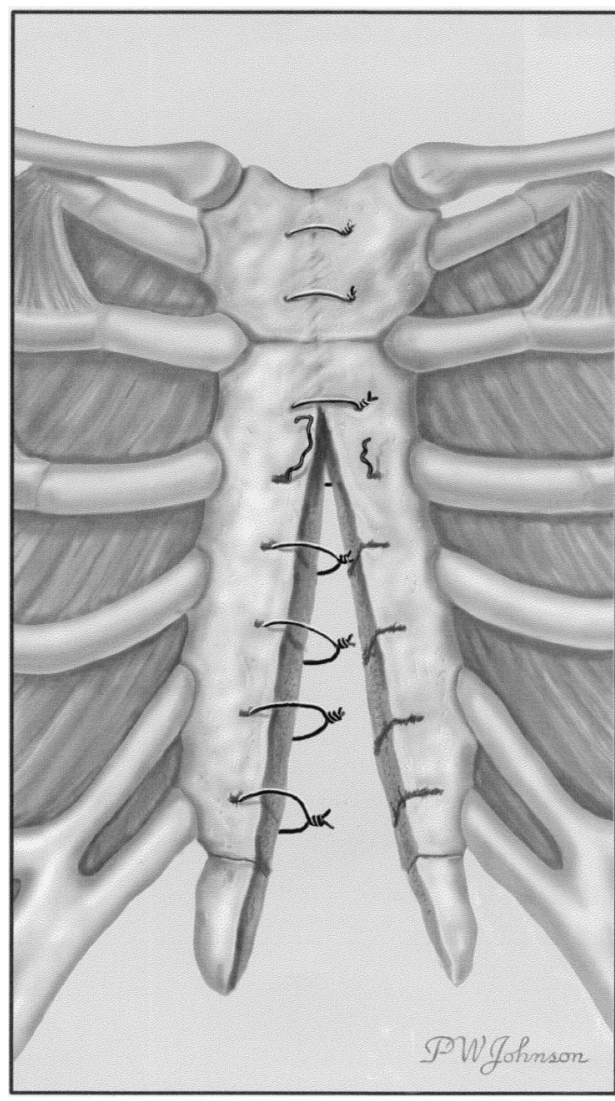

A

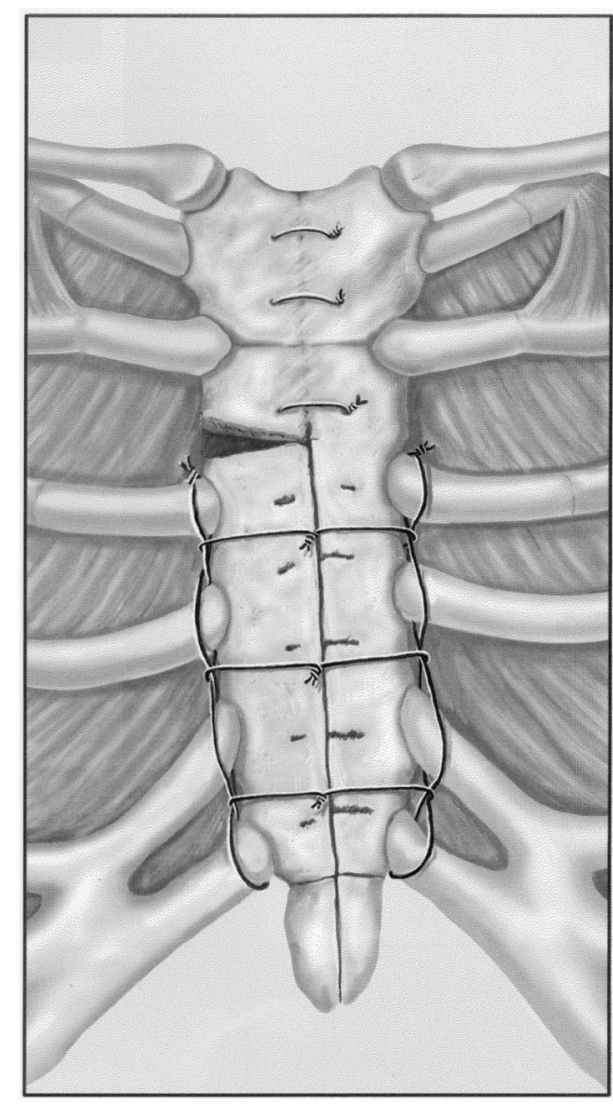

B

Fig. 2. Modified sternum weave applied in partial sternum separation. A, Before repair. B, After repair.

The purpose of this paper is to introduce a modification of our method, which in such cases assures easy and tension-free reapproximation of the separated lower sternum without the need for a full resternotomy.

Methods. The lower portion of the sternum is exposed through the previous sternotomy incision. The exposure is carried up to the level where the sternum appears to be solid. The pectoralis major muscles are detached from the sternum on both sides. All loose or broken wire sutures are removed. To promote better bone healing, the separated edges of the lower sternum are "freshed up" with rongeurs. A heavy wire suture is now passed parallel and close to the separated portion of the sternum "above and below" the same costal cartilages. This provides a double row of sutures that is repeated on the other side of the sternum. ${ }^{1}$ These sutures are carried up to the upper edge of the separation. Now the right half of the sternum is mobilized by cutting through it in a transverse fashion with an oscillating saw (Fig. 2, $A$ ). This maneuver allows easy approximation of the two halves, which now can be easily united by three or four transverse wire sutures buttressed by this transverse peristernal "weave" (Fig. 2, $B)$. The operation is completed by suturing the detached sternal edges of the pectoralis major muscles presternally. Drainage of the operative site is occasionally necessary.

This procedure was performed in several patients with chronic, noninfected, partial sternum separation. Good results and early hospital discharge were achieved in all patients.

\section{REFERENCES}

1. Robicsek F, Daugherty HK, Cook JW. The prevention and treatment of sternum separation following open-heart surgery. J Thorac Cardiovasc Surg 1977;73:267-8.

2. Robicsek F, Hamilton DA. Presternal muscle padding following midline sternotomy. J Card Surg 1989;4:299-301. 